\title{
Effect of photoionized plasma and EUV induced surface modification on physico-chemical properties and cytocompatibility of PLLA
}

\author{
J. Czwartos* , B. Budner, A. Bartnik, W. Kasprzycka, H. Fiedorowicz \\ Institute of Optoelectronics, Military University of Technology, 2 Kaliskiego Str., 00-908 Warsaw, Poland
}

Received 5 March 2020; accepted in revised form 7 May 2020

\begin{abstract}
In this work, low-temperature photoionized plasma, induced in $\mathrm{N}_{2}$ by extreme ultraviolet (EUV) pulses, was used for surface modification of poly(L-lactic acid) (PLLA). Polymer samples were irradiated with 100, 200, and 300 pulses at a $10 \mathrm{~Hz}$ repetition rate. The physical and chemical properties of PLLA samples were examined using atomic force microscopy (AFM) and X-ray photoelectron spectroscopy (XPS). The human dermal fibroblast adult cells (NHDF-Ad) were used for the cell culture and viability tests on modified PLLA surfaces. The $\mathrm{N}_{2}$-plasma and EUV treatment caused alteration of the surface morphology resulting in increased surface roughness, incorporation of nitrogen atoms, and appearing of new functional groups on the surface. Cell culture results showed an increase in the number of fibroblasts attached to the modified surfaces compared to the pristine PLLA. The modified surfaces demonstrated high cell viability and no cytotoxic effects were observed.
\end{abstract}

Keywords: biocompatible polymers, EUV, plasma treatment, XPS, fibroblasts

\section{Introduction}

In recent years, due to the enormous and ever-growing pollution of the environment as well as the decrease of oil resources, biodegradable polymers specifically the ones that are obtained from natural raw materials - are of the growing interest of many scientific groups. These materials are widely used in many areas such as packaging [1-3], wastewater treatment [4], and, in particular, biomedical and pharmaceutical applications [5-7], as well as many others. Poly(L-lactic acid) (PLLA) is one of the most popular, well-known, and the most intensively examined biodegradable polymers. This material derives from the fermentation of natural raw materials (like corn starch, wheat, sugar beet, etc.) and degrades to nontoxic products. Hence it is called 'green polymer' or merely 'environmentally-friendly'. PLLA is a thermoplastic aliphatic polyester with good mechanical properties, similarly to popular petroleum-based polymers such as, among others, polyethylene terephthalate (PET), polypropylene (PP), high-density polyethylene (HDPE) and polystyrene (PS), which PLLA can successfully replace. Due to its properties such as biocompatibility, which means it is accepted by living organisms, and non-toxicity, PLLA has played a special role in biomedical applications and has been used mainly in orthopedics, tissue engineering as well as cardio surgery or aesthetic medicine. PLLA in the 3D form, i.e. scaffold, is also used for regeneration or reconstruction of various tissues. Moreover, PLLA is used to fabricate wound dressing materials (including hydrogel ones), resorbable surgical sutures, bone implants and bone fixation devices such as plates, screws, pins, etc. [8-10] However, despite all of its apparent advantages, PLLA also has some drawbacks, which limit its biomedical 
applications. These drawbacks are mainly high hydrophobicity and lack of active functional groups for interaction with cell surface receptors [11]. It causes limited bioactivity of PLLA in terms of cell adhesion and proliferation. Pure PLLA, when implemented into human tissues, also causes slight inflammation $[12,13]$. Therefore, it is important to modify PLLA, precisely its surface properties, which can significantly improve its biomedical applicability. Multiple various PLLA modification methods have been used and reported, including surface coating [14], surface chemical modification $[15,16]$, laser irradiation [17, 18], plasma treatment $[19,20]$ and others $[21,22]$. Among them, low-temperature plasma treatment seems to be one of the universal techniques of modifying the surface layer of polymers, which does not alter its bulk properties [23]. Exposure to plasma causes effects such as surface ablation or etching, surface cleaning, crosslinking, functional group, or atom incorporation. Plasma treatment can lead to changes in the chemical composition of polymer material surface layer, being mainly the result of breaking chemical bonds and incorporating different chemical groups to the surface; the polar groups then appear, e.g., $-\mathrm{OH},-\mathrm{COOH},-\mathrm{COO},-\mathrm{C}=\mathrm{O},-\mathrm{NH}_{2}$. Another important result of plasma treatment is the change of the geometrical structure of the polymer's surface, which alters its roughness. As a consequence, surfaces with good wettability, adhesion, and biocompatibility can be obtained [24, 25]. Plasmas induced in various gases like argon, oxygen, nitrogen, fluorine, carbon dioxide etc. can be used to produce layers with unique properties required for specific applications. For example, oxygen plasma treatment can increase polymers' surface energy (their wettability), whereas fluorine plasma treatment can decrease surface energy and improve their chemical inertness. Inert gases such as neon, argon, and helium are used to introduce reactive sites on the polymer surface for subsequent copolymerization, etching, and to improve adhesion of subsequently deposited layers. Argon plasma is also often used for polymer crosslinking $[26,27]$.

The influence of plasma treatment on PLLA surface properties and cell adhesion has been widely investigated [28-30]. Different plasma gases have been used, and different cells have been cultivated on modified surfaces, with positive results in most cases. For example, some authors examined the effect of atmospheric air plasma jet treatment on the surface properties of PLLA and mouse osteoblast-like cells response [31, 32]. After plasma treatment, they observed the reduction in contact angle due to the increased hydrophilicity of the modified surfaces, an increase in the concentration of oxygen-containing functional groups, and an increase of surface roughness. They also noticed that plasma treatment of the PLLA surfaces enhanced the number and growth of adhering mouse osteoblast-like cells comparing to untreated PLLA samples. As other authors' researches show, treating PLLA surface with ammonia plasma significantly improved hydrophilicity due to incorporation of $\mathrm{NH}_{2}$ and $\mathrm{NH}_{3}$ groups into the PLLA surface structure, and, as a consequence, improvement in cell attachment and proliferation of rat calvarial cells and mouse $3 \mathrm{~T} 3$ fibroblasts was observed $[33,34]$.

In this study, low-temperature photoionized plasma, induced in $\mathrm{N}_{2}$ by extreme ultraviolet (EUV) pulses, was used for surface modification of PLLA. Plasmas were created employing a specially prepared EUV irradiation system [35]. An advantage of this system compared to standard plasma generators is that it allows for a dual-action of the low-temperature plasma and the EUV radiation. Plasma created using this method differs significantly from low-temperature plasmas created using standard methods. Standard plasma generators are usually based on an electrical discharge and are operating in a stationary regime. Plasmas of low temperature $\left(T_{\mathrm{e}} \sim 1 \mathrm{eV}\right)$ created in these generators have very low electron densities $\left(n_{\mathrm{e}}\right.$ $\sim 10^{11}-10^{13} \mathrm{~cm}^{-3}$ ) [36]. Even in the case of plasmas created under atmospheric pressure, the electron densities are low, not exceeding these values significantly. On the other hand, plasmas created by photoionization using EUV or soft X-ray pulses can have electron densities several orders of magnitude higher (can exceed $\sim 10^{18} \mathrm{~cm}^{-3}[37,38]$ ), which significantly increases the effectiveness of chemical and physical processes connected with the surface modification. As far as EUV radiation is concerned, a single EUV photon carries much more energy than photons from UV sources. An electron released as the result of the absorption of such high-energy photons is capable of breaking many molecular bonds of a polymer chain, which leads to ablation and topography changes of the sample surface. An absorption length of the EUV radiation in any polymer is in the order of tens of nanometers. It means that the photon-induced changes in irradiated material can appear only 
in a near-surface layer. For surface modification of many materials, it could be a significant advantage over the use of the UV source, where the surface penetration depth is $10-500 \mu \mathrm{m}$ [39]. In our earlier works, it was demonstrated that the simultaneous treatment of fluoropolymers with the EUV radiation and nitrogen plasma significantly modified their chemical structures $[40,41]$. In this paper, the detailed chemical analysis of modified PLLA carried out based on high-resolution XPS spectra analysis is presented. Change in surface geometry obtained and its roughness was investigated using atomic force microscopy (AFM). The influence of physico-chemical changes of modified PLLA samples on the behavior of human dermal fibroblasts adult cells (NHDF-Ad) was evaluated.

\section{Materials and methods}

\subsection{Modification of PLLA foils using low-temperature photoionized plasma induced in nitrogen by extreme ultraviolet (EUV) pulses}

Biaxially oriented PLLA foils with a thickness of 50 $\mu \mathrm{m}$ (Goodfellow Cambridge Limited, UK) and semicrystalline structure $(\sim 60-70 \%)$ were modified in these experiments. The modifications were performed using a $10 \mathrm{~Hz}$ laser-plasma EUV source. This source has been designed in our laboratory for micromachining and surface modification of polymers and based on a double stream gas puff target irradiated with a 4 ns/0.8 J Nd:YAG laser pulses (NL $303 \mathrm{HT}$, EXPLA, Lithuania) [42]. The target was created as a result of a pulsed injection of a small portion of xenon gas into a hollow stream of helium $(\mathrm{Xe} / \mathrm{He}$ target) using an electromagnetic valve system equipped with a double nozzle set-up. The laser beam focused on the stream of Xe created high-temperature plasma. The focusing conditions, as well as parameters of the plasma, were chosen to obtain the maximum radiation intensity in the EUV spectral range. The EUV radiation was focused on employing a gold-plated ellipsoidal mirror (RITE s.r.o., Czech Republic). This mirror allowed us to efficiently collect and focus the Xe plasma radiation in the wavelength range of $\lambda=9-70 \mathrm{~nm}$. The maximum of intensity occurred at a wavelength of $\lambda=10 \pm 1 \mathrm{~nm}$. The EUV fluence at the center of the focal spot exceeded $60 \mathrm{~mJ} / \mathrm{cm}^{2}$. The EUV beam was used for photoionization of the nitrogen gas, which was injected into the region of the focal spot, perpendicularly to the optical axis of the irradiation system using an auxiliary gas-puff valve [40]. The EUV induced, lowtemperature nitrogen plasma formed this way, together with a not absorbed part of the EUV radiation, was used for the surface treatment of PLLA samples. The samples exposed were placed on the XYZ movable stage and located $3 \mathrm{~mm}$ downstream of the EUV collector focal plane. The surfaces of PLLA were irradiated with 100,200 , and 300 pulses at a $10 \mathrm{~Hz}$ repetition rate. The modified area was circle-like shaped with approximately $2 \mathrm{~mm}$ in diameter. The area of this size was large enough for carrying out the morphological characterizations (AFM) and cell culture observations. For the XPS and MTT examinations to be performed, the areas of size $\sim 0.7 \mathrm{~cm} \times 1.2 \mathrm{~cm}$ ( 15 spots in total) and $\sim 0.4 \mathrm{~cm} \times 0.4 \mathrm{~cm}(4$ spots in total), respectively, were modified.

\subsection{Chemical analysis (XPS)}

Chemical analysis of PLLA samples modified with 100, 200, and 300 pulses and an untreated reference sample was carried out using X-ray photoelectron spectroscopy (XPS). Spectrometer XPS (Prevac, Poland) equipped with an analyzer SCIENTA R3000 (VG Scienta, Sweden) and X-ray lamp with the Al $\mathrm{K}_{\alpha}$ anode (Prevac, Poland) was used. During the measurements, the pressure in the ultra-high vacuum analysis chamber of the XPS system was about $3 \cdot 10^{-9}$ mbar.

The reference sample $i$. e. non-modified PLLA foil was cleaned using ethanol, while modified PLLA samples were measured after EUV modification without any cleaning treatment. For all PLLA samples, the low-resolution survey spectra, in a wide range of binding energy of $0-1486.6 \mathrm{eV}$ with a $1 \mathrm{eV}$ step and pass energy of $200 \mathrm{meV}$, were registered. For detailed chemical analysis, high-resolution spectra in the narrow ranges of binding energy with a $40 \mathrm{meV}$ step and pass energy of $100 \mathrm{meV}$ for each band $\mathrm{O} 1 \mathrm{~s}(528-538 \mathrm{eV}), \mathrm{N} 1 \mathrm{~s}(395-405 \mathrm{eV})$ and C1s (281-292 eV) were recorded. The peaks O1, $\mathrm{N} 1 \mathrm{~s}$, and $\mathrm{C} 1 \mathrm{~s}$ were fitted using CasaXPS software. The background of linear type and GaussianLorentzian (G-L) line shape (GL 50 for O1s, GL 60 for N1s, and GL 55 for C1s) were fitted for all these bands. All XPS spectra measured were shifted in such a way that the maximum of the $\mathrm{CH}_{3}$ peak was at $285 \mathrm{eV}$. 


\subsection{Morphological characterization (AFM)}

The morphology of non-modified and modified PLLA samples was studied using an atomic force microscope (AFM) (NT-MDT Spectrum Instruments, Russia). The measurements were performed in a semicontact mode at ambient conditions using standard AFM probe (HQ:NSC 15/Al BS, MikroMasch, Bulgaria) featuring pyramidal silicon tip with a curvature radius of $\sim 8 \mathrm{~nm}$. The cantilever was characterized by force constant ranged from 20 to $80 \mathrm{~N} / \mathrm{m}$ with the resonance frequency of $265-410 \mathrm{kHz}$. The topographies collected had a scan size of $50 \mu \mathrm{m} \times 50 \mu \mathrm{m}$ with a resolution of 256 points per line. The cross-section analysis, as well as average surface roughness calculations, were carried out using Image Analysis software provided by NT-MDT Spectrum Instruments. This examination allowed us to evaluate the structure of examined PLLA surfaces and their relations with the number of pulses used.

\subsection{Cell culture and viability tests}

\subsubsection{Cell culture}

The human dermal fibroblast adult cells, NHDF-Ad (CC-2511, Lonza, Japan), were used for in vitro tests on non-modified and modified PLLA surfaces. The cells were maintained in FGM $^{\mathrm{TM}}-2$ BulletKit ${ }^{\mathrm{TM}}$ Growth Media (Lonza, Japan) containing 2\% fetal bovine serum (FBS, Lonza, Japan). This medium was used to perform all the operations described in paragraphs 2.4.2 and 2.4.3. The cells were cultivated in a humidified incubator in which the atmosphere contained $5 \% \mathrm{CO}_{2}$, and the temperature was $37^{\circ} \mathrm{C}$. The cells were fed every three days and subcultured using Trypsin-EDTA solution and soybean trypsin inhibitor (Lonza, Japan).

The non-modified and modified PLLA samples were cut into squares with a side of $4 \mathrm{~mm}$. Each square was sterilized for $15 \mathrm{~min}$. in $70 \%$ ethanol and then air-dried. This procedure ensured that the material contacting cells was decontaminated.

\subsubsection{Fluorescent microscopy}

The samples of the PLLA foil was inserted into 24well plate, then $2 \cdot 10^{4}$ NHDF-Ad cells were seeded into each well (density $10^{4}$ cells $\cdot \mathrm{cm}^{-1}$ ) and the volume of medium was filled up to $1 \mathrm{ml}$. The cells were seeded on two samples for each type of treatment: 100,200 , and 300 pulses plus non-treated and control, in two separate wells on each sample. The cells with the polymer and control samples were incubated for $24 \mathrm{~h}$ at a temperature of $37^{\circ} \mathrm{C}$ in order to attach them to the surface of polymers and stained with fluorescent dyes (LIVE/DEAD ${ }^{\text {TM }}$ Viability/Cytotoxicity Kit, for mammalian cells, Invitrogen ${ }^{\mathrm{TM}}$, USA). Two dyes were used: 1) cell-permeant, nonfluorescent calcein AM that is converted by intracellular esterases to fluorescent calcein in live cells, and 2) ethidium homodimer-1 that binds with nuclear acids in dead cells when their plasma membrane loses integrity. The medium was gently removed from the polymer with cells attached to it, and the staining solution was added to each well. The whole procedure was in line with the manufacturer's protocol. NHDFAd cells were visualized using a confocal microscope (LSM 700 Axio Observer.Z1 Zeiss, Germany) immediately after staining $\left(15 \mathrm{~min}, 37^{\circ} \mathrm{C}\right)$.

\subsubsection{Cell viability}

MTT assay (Invitrogen ${ }^{\mathrm{TM}}$, USA) was performed to check whether the cells were still viable after contact with non-modified and modified polymers. The metabolic activity of cells in the MTT test was measured by the redox potential, whereby cells convert the water-soluble MTT reagent (3-(4,5-dimethylthiazol-2-yl)-2,5-diphenyltetrazolium bromide) to a water-insoluble formazan. The more vital the cell, the more the MTT reagent is reduced to a pigmented, purple product. After solubilization, the absorbance of the formazan is measured. MTT cytotoxicity test was performed based on the method of incubating cells with the extract of materials described in ISO 10993-5 standards. NHDF-Ad cells were seeded in 96-well plates $\left(5 \cdot 10^{3}\right.$ cells per well). Each square of the modified and non-modified sterilized PLLA was inundated with $100 \mu \mathrm{l}$ of complete cell culture medium. NHDF-Ad cells and pieces of polymer were incubated in the same conditions (at $37^{\circ} \mathrm{C}, 5 \% \mathrm{CO}_{2}$ ) for 24 hours. After this time, the cell medium was replaced with the extract of materials, and the cells were again incubated for another 24 hours. The control containing only cells with FGM $^{\mathrm{TM}}$-2 medium was also included. MTT working solution (5\% of volume) was prepared, immediately before it has been used, by adding MTT stock solution (12 mM 3-(4,5dimethylthiazol-2-yl)-2,5-diphenyltetrazolium bromide dissolved in phosphate-buffered saline) to complete growth medium. The culture medium and extract of materials were removed, replaced with $100 \mu 1$ of MTT working solution, and incubated at $37^{\circ} \mathrm{C}, 5 \% \mathrm{CO}_{2}$ for 3 hours. After labeling the cells 
with MTT, all medium from the wells was carefully removed, formazan was dissolved by adding $100 \mu \mathrm{l}$ $\operatorname{DMSO}(0,01 \mathrm{M}$ solution dimethyl sulfoxide) and the optical density was determined using a microplate absorbance reader (SpectraMax i3, Molecular Devices, USA). The absorbance was read at $540 \mathrm{~nm}$. Samples were prepared in nine replicates. Viability of NHDF-Ad cells was calculated according to Equation (1):

Viability $=\frac{\sum_{\mathrm{n}} A_{\text {sample }}}{\sum_{\mathrm{n}} A_{\text {control }}} \cdot 100 \%$

where $A_{\text {sample }}$ is the absorbance value of the tested sample at $540 \mathrm{~nm}, A_{\text {control }}$ is the absorbance value of control at $540 \mathrm{~nm}, n$ is the number of replicates.
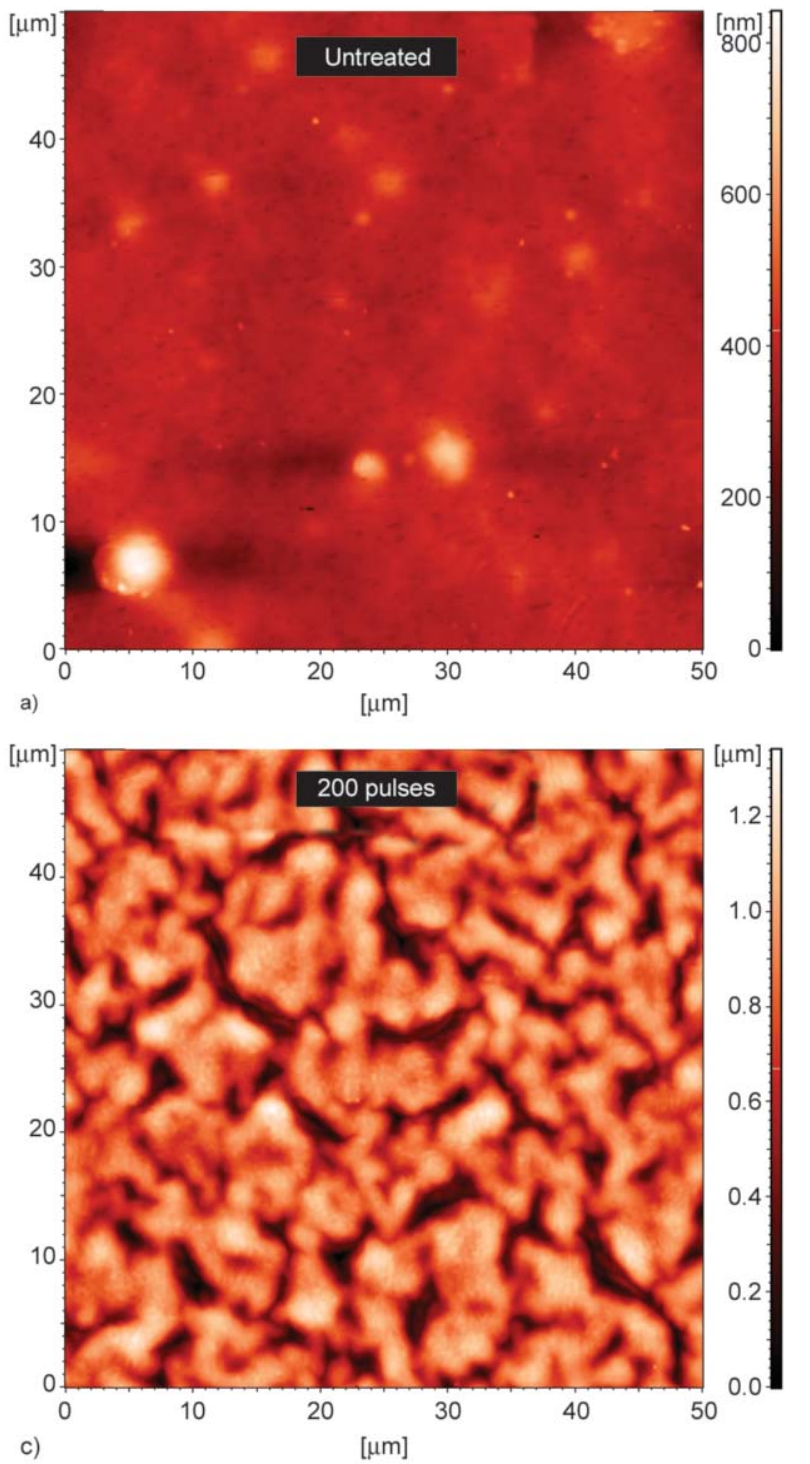

\section{Results and discussion}

\subsection{Changes in surface morphology}

The polymer irradiation induces morphological changes of surface, such as the formation of nano- and micropatterns. Their characteristics (shape, height, size, or orientation) strongly depend on the EUV fluence in a single pulse, the number of pulses irradiated on the surface, as well as the chemical structure of polymer, its heat capacity, material sensitivity or ablation threshold value. The influence of the photoionizing plasma and EUV treatment on the surface morphology and roughness of PLLA was determined using the AFM method in semi-contact mode. The structures observed in this experiment were obtained for the near-maximum fluence of $\sim 60 \mathrm{~mJ} / \mathrm{cm}^{2}$. Such a fluence is sufficient for the ablation of most polymers. Figure 1 shows the AFM topographies (with a
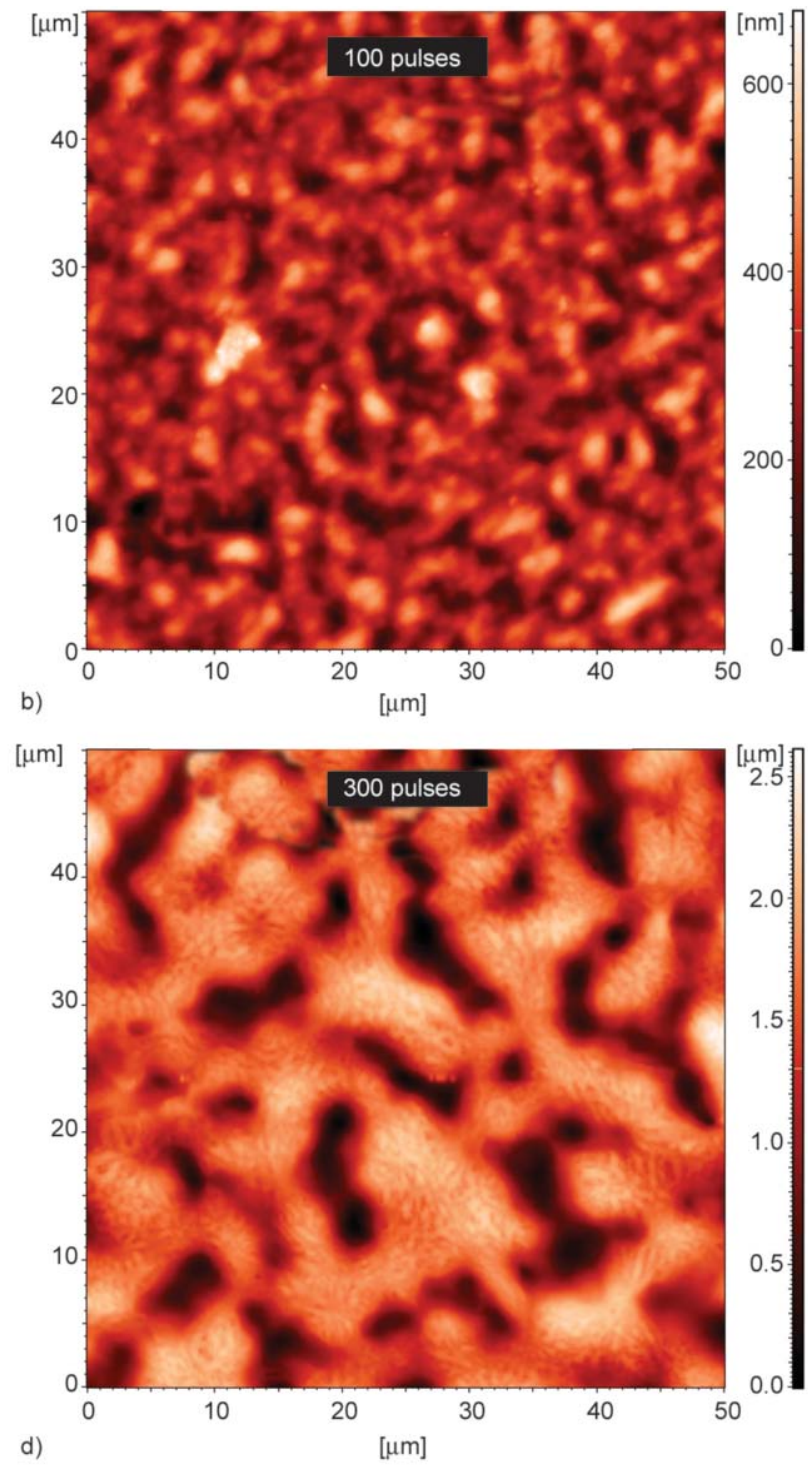

Figure 1. AFM topographies of untreated PLLA surface (a) and PLLA surface modified with 100, 200 and 300 pulses (b-d). 
scan size of $50 \mu \mathrm{m} \times 50 \mu \mathrm{m})$ of non-modified PLLA surface and PLLA surface modified with 100, 200, and 300 pulses. As shown on the figure, the original surface of the non-modified polymer was smooth, with no specific pattern and with rarely located bulges of varying size and height. The surface of the samples irradiated with $\mathrm{N}_{2}$-plasma and EUV significantly changed. Specific micro-pattern appeared on their surfaces, which was quite regular, and the higher number of pulses, the more definite the pattern was, and the higher its structures were.

Examination of PLLA foils using AFM enabled not only to image patterns formed on the sample surfaces after irradiation but also to measure their height, size and calculate their average surface roughness. Heights of the surface patterns were measured through crosssection analysis - Figure 2, where the profile of the PLLA structure was obtained along with a single, selected line. The average surface roughness $\left(R_{\mathrm{a}}\right)$ values were averaged from four measurements from each one sample. As Figure 2 shows, the untreated PLLA surface is represented by a moderately flat line, which confirms what has been shown in Figure 1: that the sample's surface is rather smooth and the height of its natural irregularities is less than $100 \mathrm{~nm}$. The average surface roughness calculated for this sample was $29 \pm 2 \mathrm{~nm}$. Height of the structures observed on the PLLA surface treated with 100 pulses, having the form of slight crinkles, do not exceed $300 \mathrm{~nm}$ and Ra calculated for this surface was $68 \pm 3 \mathrm{~nm}$. Heights of the structures formed on PLLA surfaces treated with 200 and 300 pulses were multiple times higher comparing to PLLA treated with 100 pulses and reached $\sim 1$ and $\sim 1.5 \mu \mathrm{m}$, respectively. For the two latter cases, it was noticed that wall-like structures

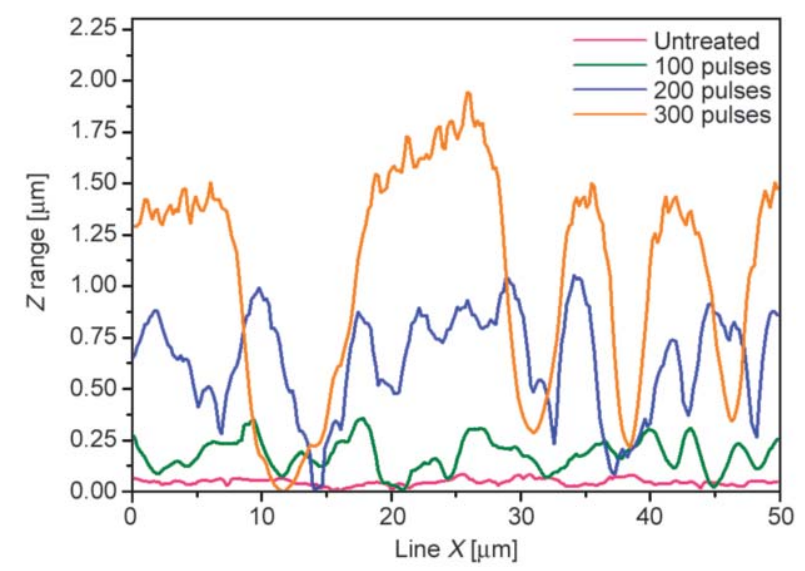

Figure 2. Cross section profiles obtained along selected line for untreated PLLA and PLLA modified with 100, 200 and 300 pulses. observed on the surfaces start to occur quasi-regularly, i.e. these structures appeared in a repeatable way. $R_{\mathrm{a}}$ values for PLLA treated with 200 and 300 pulses were $174 \pm 14$ and $358 \pm 7 \mathrm{~nm}$, respectively. Therefore, the more pulses used, the higher structures were and their average surface roughness.

The mechanism of forming such specific non-uniform morphology on the PLLA surface is quite complicated. The material used in this experiment exhibited $\sim 60-70 \%$ crystallinity. Therefore, various values of ablation thresholds of crystalline and amorphous domains undoubtedly influenced the formation of such complex ablated surfaces. Also, the energy delivered with a huge amount of nanosecond intensive EUV pulses (100, 200, and 300), which strongly heated the sample, led to local softening of a thin layer of PLLA (when reaching its $T_{\mathrm{g}}$, i.e. $\sim 55^{\circ} \mathrm{C}$ ), melting, and finally crinkling. At the same time, an increasing number of EUV pulses used (increasing temperature) led to the creation of volatile fractions of polymer chains just under the surface, which resulted in increasing non-uniform swelling of near-surface PLLA layer. Another contribution to the formation of specific irregularities on the PLLA surfaces was the relaxation of frozen stress fields in the polymer originating from the production process. As presented in [43], the formation of different structures depends on the stretching of polymer foil. Irradiating of uniaxially stretched foils results in wall-type structures. Irradiating of biaxially stretched foils, which were also used in this research, results in nap-type structures with no specific direction. In the case of annealed (unstretched) foils, such structures are not formed, and the surface is smooth [44, 45].

The results discussed in this section correspond with the results obtained by other researchers who used to modify various polymer surfaces with plasma treatment and/or laser, EUV irradiation [38, 46-51]. Similarly, results of these examinations also showed changes in surface roughness comparing to untreated polymer surfaces and, as a result, the formation of various types of self-organized nano- and/or microstructures, height and pattern of which was dependent not only from the number of irradiation pulses used or time of plasma treatment but also from the chemical structure of polymers, their degree of crystallinity and ordering of polymer chains. The structures observed and described in the researches were, among others, of conical, wall-, nap-, ripple-, wormlike, etc. 


\subsection{Chemical analysis}

The analysis of the chemical composition and structure of PLLA polymer surfaces modified with 100 , 200, and $300 \mathrm{EUV}$ pulses in the presence of nitrogen was carried out based on the high-resolution XPS measurements. To determine chemical changes that took place on the surface due to modifications, the reference material, i.e. non-modified PLLA surface, was analyzed first. For the reference material's highresolution $\mathrm{C} 1 \mathrm{~s}$ and $\mathrm{O} 1 \mathrm{~s}$ bands registered, the model of peaks referring to its chemical structure was developed. Therefore three peaks were modeled for the $\mathrm{C} 1 \mathrm{~s}$ band, which related to three functional groups observed in the original PLLA structure (Figure 3a): $\mathrm{CH}_{3}$ (the carbon atom marked as $\mathrm{C} 1$ ) at $285 \mathrm{eV}$ (FWHM 1.5-1.6 eV, 24 at.\%), O-C ${ }^{*}-\mathrm{COO}$ (the carbon atom marked as $\mathrm{C} 2)$ at $287 \mathrm{eV}$ (FWHM 1.5$1.7 \mathrm{eV}, 20.2$ at. \%) and $\mathrm{O}-\mathrm{C}^{*}=\mathrm{O}$ (the carbon atom marked as C3) at $289.1 \mathrm{eV}$ (FWHM $1.3-1.6 \mathrm{eV}$, 17.7 at.\%). In the $\mathrm{O} 1 \mathrm{~s}$ band, the following peaks were fitted: $\mathrm{O}^{*}=\mathrm{C}-\mathrm{O}-\mathrm{C}$ (the oxygen atom marked as O1) at $532 \mathrm{eV}$ (FWHM 1.6-1.8 eV, 17.7 at.\%) and $\mathrm{C}-\mathrm{O}^{*}-\mathrm{C}=\mathrm{O}$ (the oxygen atom marked as $\mathrm{O} 2$ ) at $533.4 \mathrm{eV}$ (FWHM 1.8-1.9 eV, 20.2 at.\%) (Figure 3b). As shown in Figure 3b, the additional peak was also modeled at about $534.2 \mathrm{eV}$, correlated with $\mathrm{O}-\mathrm{H}$ groups coming from the water molecules adsorbed on the PLLA surface. The total content of the carbon and oxygen was taken as 100 at.\%. The model developed for the reference PLLA described the nonmodified material appropriately. Then this model was used to analyze the XPS spectra of the samples modified by the dual action of photoionized plasma and EUV irradiation. Because the envelope of the modified samples' $\mathrm{C} 1 \mathrm{~s}$ and $\mathrm{O} 1 \mathrm{~s}$ bands changed significantly, not only the reference model peaks but also additional peaks were added to the $\mathrm{C} 1 \mathrm{~s}$ and $\mathrm{O} 1 \mathrm{~s}$ bands, which described changes in the chemical composition of the polymer surface resulting from EUV and plasma irradiation. Additional N1s band occurred, too, as a result of modification during which nitrogen atoms coming from $\mathrm{N}_{2}$-plasma were incorporated into the PLLA surface structure. This band was modeled with 3 peaks, parameters of which (peak positions and FWHMs) were determined through the analysis of the spectra registered for the polymers containing nitrogen in their structure such as polyurethane, nylon, and Kapton. Figure 4 shows the high-resolution XPS spectra of $\mathrm{C} 1 \mathrm{~s}, \mathrm{~N} 1 \mathrm{~s}$, and O1s bands of PLLA treated with 100, 200, and 300 pulses. Parameters of the peaks added, i.e. peak maximum, FWHM, and atomic percentage, were presented in Table 1. The peaks introduced correspond to the most probable functional groups that could appear as a result of breaking and modifying PLLA mers with EUV radiation. The following new peaks were introduced: - $\mathrm{C}-\mathrm{C}=\mathrm{C}-(\mathrm{C} 4)-$ at $284.6 \mathrm{eV}$ (FWHM 1.5-1.6 eV) - this peak represents carbon atoms in repeating units of PLLA from which the oxygen atoms were detached as a result of the EUV and plasma interaction. In fact, this peak can represent a number of random, various chemical structures containing only carbon and hydrogen.

- $\mathrm{CH}_{3}-\mathrm{C}^{*}-\mathrm{COO}$ - (C5) - at 285.4 eV (FWHM 1.5$1.7 \mathrm{eV}$ ) - this chemical structure can appear as the result of breaking the $\mathrm{C}-\mathrm{O}$ bond in PLLA structure.

- $\mathrm{C}-\mathrm{N}$ - (C6) - at $286 \mathrm{eV}$ (FWHM 1.5-1.6 eV) the presence of this peak is a result of incorporating nitrogen atoms into PLLA structure. It is assumed that nitrogen complements empty bonds being the result of detaching oxygen atoms from PLLA structure. Usually, the peak is registered in

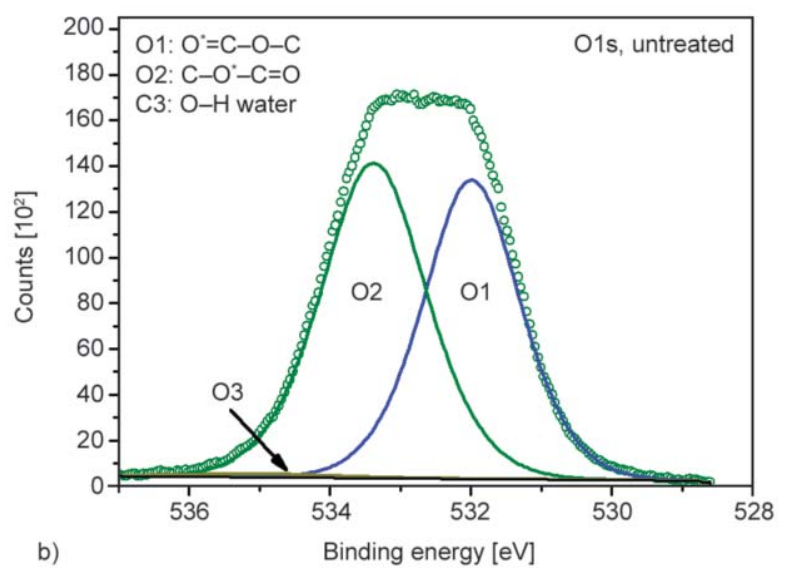

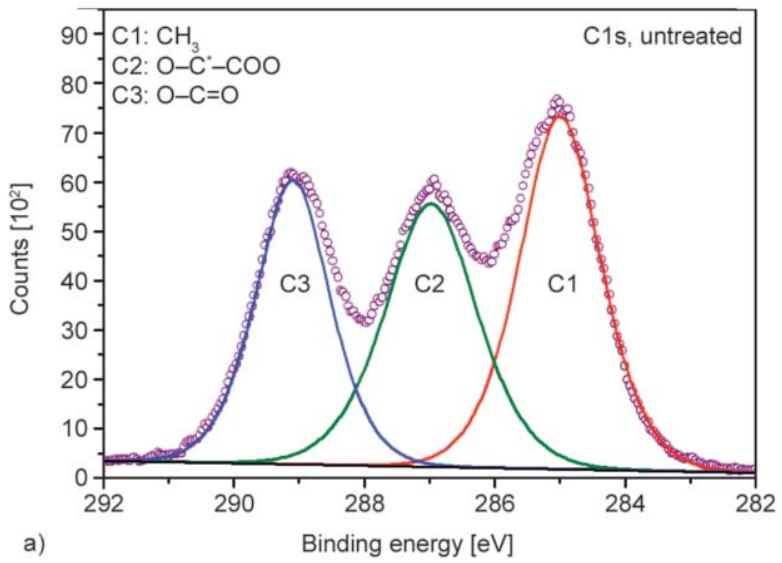

Figure 3. XPS spectra of non-modified PLLA: C1s band (a) and O1s band (b). 

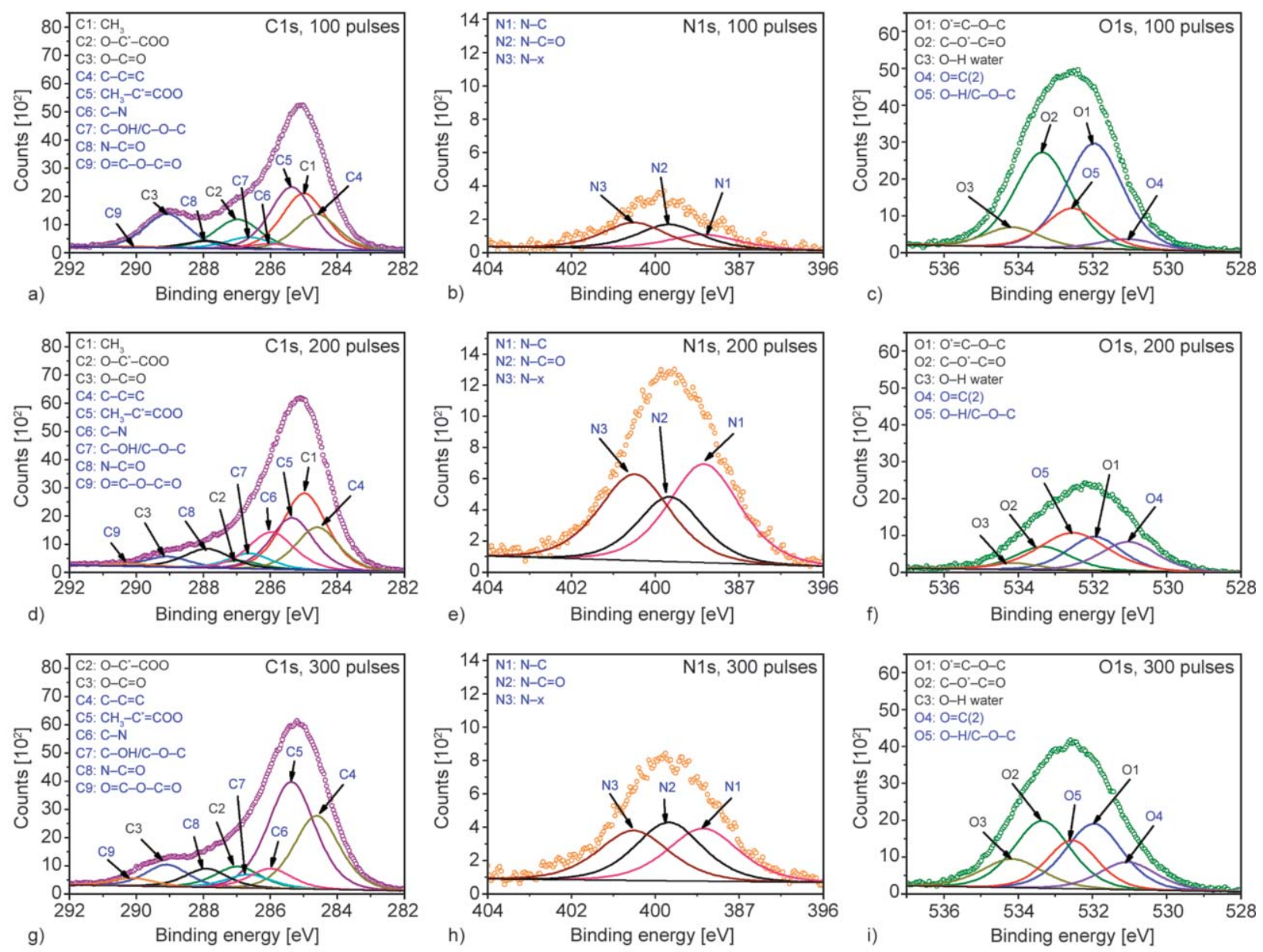

Figure 4. XPS bands of modified PLLA: C1s band for 100 pulses (a), N1s band for 100 pulses (b), O1s for 100 pulses (c), C1s band for 200 pulses (d), N1s band for 200 pulses (e), O1s band for 200 pulses (f), C1s band for 300 pulses (g), N1s band for 300 pulses (h), O1s band for 300 pulses (i).

the range of $286-287 \mathrm{eV}$, however, some references say that at the same range also the peaks $\mathrm{C}=\mathrm{N}$ and $\mathrm{C} \equiv \mathrm{N}$ are placed [52].

- $\mathrm{C}-\mathrm{OH}$ or $(\mathrm{C}-\mathrm{O}-\mathrm{C})-(\mathrm{C} 7)-$ at $286.6 \mathrm{eV}$ (FWHM $1.5-1.7 \mathrm{eV}$ ) - the typical functional groups, which occur mostly during modification of the polymer surface using laser or plasma irradiation [53]. As the binding energy values of these two peaks are very close, they are considered as one peak (it cannot be identified whether it is specifically $\mathrm{C}-\mathrm{OH}$ or specifically $\mathrm{C}-\mathrm{O}-\mathrm{C})$.

- $\mathrm{N}-\mathrm{C}=\mathrm{O}-(\mathrm{C} 8)-$ at $287.9 \mathrm{eV}(\mathrm{FWHM} 1.5-1.7 \mathrm{eV})$ - this group exists in the polymers which contain in their structure the nitrogen atoms, such as polyurethane, Kapton, and nylon. The presence of the group has been confirmed by the shape and position of N1s band [54].

- $\mathrm{O}=\mathrm{C}^{*}-\mathrm{O}-\mathrm{C}=\mathrm{O}-(\mathrm{C} 9)-$ at $290.1 \mathrm{eV}$ (FWHM $1.5-1.7 \mathrm{eV}$ ) - the peak binding energy is $1 \mathrm{eV}$ higher than the binding energy of the $\mathrm{C} 3$ peak in the reference PLLA structure and, most probably, can represent the chemical structure proposed.

- $\mathrm{O}-\mathrm{H}$ water - $(\mathrm{O} 3)$ - at $534.2 \mathrm{eV}$ (FWHM 1.7$2.4 \mathrm{eV}$ ) - similarly to the non-modified PLLA, this peak most probably comes from $\mathrm{OH}$ groups of the water adsorbed on the surface of samples.

- $\mathrm{O}=\mathrm{C}(2)-(\mathrm{O} 4)$ - at $531 \mathrm{eV}(\mathrm{FWHM} 1.8-1.9 \mathrm{eV})$ - oxygen-carbon double bond exists in PLLA material. As the position of this peak is shifted by $\sim 1 \mathrm{eV}$ compared to the peak of the same group in non-modified PLLA, it is assumed that the chemical surrounding of a carbon atom with which the oxygen atom considered is bonded, has significantly changed. It is assumed that the bonds in PLLA C-O-C structure have been broken, and, as a result, the binding energy of the oxygen-carbon double bond should decrease.

- $\mathrm{O}-\mathrm{H} / \mathrm{C}-\mathrm{O}-\mathrm{C}-(\mathrm{O} 5)$ - at $532.5 \mathrm{eV}$ (FWHM 1.6$2.2 \mathrm{eV}$ ) - the peak in O1s band, complementary to the peak marked similarly in $\mathrm{C}$ 1s band. 
Table 1. Binding energy, FWHM range and atomic concentration of different functional groups for pristine PLLA and PLLA modified with 100, 200 and 300 pulses.

\begin{tabular}{|c|c|c|c|c|c|c|c|}
\hline $\begin{array}{c}\text { Symbol of the } \\
\text { peak }\end{array}$ & $\begin{array}{l}\text { Chemical } \\
\text { group }\end{array}$ & $\begin{array}{c}\text { Position } \\
{[\mathrm{eV}]}\end{array}$ & $\begin{array}{c}\text { FWHM } \\
{[\mathrm{eV}]}\end{array}$ & $\begin{array}{c}\text { PLLA-untreated } \\
\text { [at. \%] }\end{array}$ & $\begin{array}{l}\text { PLLA-100 } \\
\text { [at. \%] }\end{array}$ & $\begin{array}{l}\text { PLLA-200 } \\
\text { [at. \%] }\end{array}$ & $\begin{array}{l}\text { PLLA-300 } \\
\text { [at. \%] }\end{array}$ \\
\hline $\mathrm{C} 1$ & $\mathrm{CH}_{3}$ & 285.0 & $1.5-1.6$ & 24.0 & 17.0 & 23.9 & - \\
\hline $\mathrm{C} 2$ & $\mathrm{O}-\mathrm{C}^{*}-\mathrm{COO}$ & 287.0 & $1.5-1.7$ & 20.2 & 9.2 & 2.3 & 5.8 \\
\hline $\mathrm{C} 3$ & $\mathrm{O}-\mathrm{C}=\mathrm{O}$ & 289.1 & $1.3-1.6$ & 17.7 & 10.3 & 3.2 & 5.7 \\
\hline $\mathrm{C} 4$ & $\mathrm{C}-\mathrm{C}=\mathrm{C}$ & 284.6 & $1.5-1.6$ & - & 10.4 & 12.7 & 20.2 \\
\hline $\mathrm{C} 5$ & $\mathrm{CH}_{3}-\mathrm{C}^{*}-\mathrm{COO}$ & 285.4 & $1.5-1.7$ & - & 18.4 & 15.4 & 30.4 \\
\hline C6 & $\mathrm{C}-\mathrm{N}$ & 286.0 & $1.5-1.6$ & - & 1.6 & 11.7 & 5.1 \\
\hline C7 & $\mathrm{C}-\mathrm{OH} / \mathrm{C}-\mathrm{O}-\mathrm{C}$ & 286.6 & $1.5-1.7$ & - & 3.7 & 4.6 & 3.7 \\
\hline $\mathrm{C} 8$ & $\mathrm{~N}-\mathrm{C}=\mathrm{O}$ & 287.9 & $1.5-1.7$ & - & 0.8 & 2.3 & 1.8 \\
\hline C9 & $\mathrm{O}=\mathrm{C}-\mathrm{O}-\mathrm{C}=\mathrm{O}$ & 290.1 & $1.5-1.7$ & - & 0.4 & 0.8 & 2.0 \\
\hline $\mathrm{O} 1$ & $\mathrm{O}^{*}=\mathrm{C}-\mathrm{O}-\mathrm{C}$ & 532.0 & $1.6-1.8$ & 17.7 & 10.3 & 3.2 & 5.7 \\
\hline $\mathrm{O} 2$ & $\mathrm{C}-\mathrm{O}^{*}-\mathrm{C}=\mathrm{O}$ & 533.4 & $1.8-1.9$ & 20.2 & 9.2 & 2.3 & 5.8 \\
\hline $\mathrm{O} 3$ & $\mathrm{O}-\mathrm{H}$ water & 534.2 & $1.7-2.4$ & 0.3 & 1.9 & 0.6 & 2.7 \\
\hline $\mathrm{O} 4$ & $\mathrm{O}=\mathrm{C}(2)$ & 531.0 & $1.8-1.9$ & - & 1.0 & 2.9 & 2.4 \\
\hline O5 & $\mathrm{O}-\mathrm{H} / \mathrm{C}-\mathrm{O}-\mathrm{C}$ & 532.5 & $1.6-2.2$ & - & 3.7 & 4.6 & 3.7 \\
\hline N1 & $\mathrm{N}-\mathrm{C}$ & 398.8 & $2.0-2.1$ & - & 0.5 & 3.9 & 1.7 \\
\hline $\mathrm{N} 2$ & $\mathrm{~N}-\mathrm{C}=\mathrm{O}$ & 399.7 & $1.8-1.9$ & - & 0.8 & 2.3 & 1.8 \\
\hline N3 & $\mathrm{N}-\mathrm{x}$ & 400.5 & $1.8-2.0$ & - & 0.8 & 3.4 & 1.6 \\
\hline
\end{tabular}

The following peaks were fitted in N1s band:

- N-C - (N1) - at 398.8 eV (FWHM 2.0-2.1 eV) the peak in N1s band, complementary to the peak marked similarly in $\mathrm{C} 1 \mathrm{~s}$ band.

- $\mathrm{N}-\mathrm{C}=\mathrm{O}-(\mathrm{N} 2)$ - at 399.7 eV (FWHM 1.8-1.9 eV) - the peak in N1s band, complementary to the peak marked similarly in $\mathrm{C} 1 \mathrm{~s}$ band.

- $\mathrm{N}-\mathrm{x}$ - (N3) - at $400.5 \mathrm{eV}$ (FWHM 1.8-2.0 eV) this peak is difficult to interpret as the functional group it represents cannot be precisely given. However, on the basis of references and results of the XPS analysis of the polymers containing nitrogen in their structure (PU, Kapton, nylon), it can be assumed that nitrogen atom is bonded with carbon whose chemical surrounding contains at least two oxygen atoms (strongly interacting with nitrogen atom). Some of the references say that this peak can represent $\mathrm{N}-\mathrm{O}$ bond in which the binding energy of the nitrogen atom exceeds $400 \mathrm{eV}$ [55].

As Figure 4 and Table 1 show, photoionizing plasma and EUV irradiation strongly affect the original chemical structure of PLLA. A significant decrease in the amount of the oxygen-containing functional groups can be seen, where oxygen is single-bonded (peak marked as C2) as well as double-bonded with carbon (peak marked as C3). Content of chemical groups represented by the $\mathrm{C} 2$ and $\mathrm{C} 3$ peaks decreases from 20.2 and 17.7 at.\%, respectively, for non-modified PLLA to 2.3 and 3.2 at.\%, respectively, for PLLA treated with 200 pulses. At the same time, multiple new chemical structures represented by peaks marked C4-C9 appear, as well as peaks related to them in $\mathrm{O} 1 \mathrm{~s}$ and N1s bands. The chemical groups represented by the peaks marked as $\mathrm{C} 4$ and $\mathrm{C} 5$, at 284.6 and $285.4 \mathrm{eV}$, respectively, are the ones of the maximum content in the samples subject to modification and where the carbon atoms in their structure are not directly bonded with oxygen or nitrogen. The content of these groups reaches maximum values i.e. $20.2 \%$ for C4 and $30.4 \%$ for C5 for PLLA sample treated with 300 pulses. These chemical groups appear as a result of a significant decrease in the amount of oxygen on the samples' surfaces. $\mathrm{N}_{2}$-plasma and EUV treatment is a destructive process to a certain extent as it leads to the spontaneous breaking of chemical bonds and creating new random chemical structures. Due to the presence of reactive nitrogen species, it leads to the incorporation of nitrogen into polymers' structure. C6 and C8 peaks in C1s band, at 287.9 and $286 \mathrm{eV}$, respectively, have been assigned to the carbon chemical groups with nitrogen atoms in their structure. The content of these groups is proportional to the content of nitrogen in the surface of samples examined and reaches a maximum value for 200 pulses (11.7 and 2.3 at.\% for C6 and $\mathrm{C} 8$ peaks, respectively). The content of the rest of the peaks - C7 and C9 - is the lowest and does not exceed 4.6 at. $\%$. 
Table 2. Atomic concentration of carbon, oxygen and nitrogen for the pristine PLLA and PLLA modified with 100,200 and 300 pulses.

\begin{tabular}{|c|c|c|c|c|}
\hline Elements & $\begin{array}{c}\text { PLLA } \\
\text { untreated } \\
\text { [at. \%] }\end{array}$ & $\begin{array}{c}\text { PLLA-100 } \\
\text { [at. \%] }\end{array}$ & $\begin{array}{c}\text { PLLA-200 } \\
\text { [at. \%] }\end{array}$ & $\begin{array}{c}\text { PLLA-300 } \\
\text { [at. \%] }\end{array}$ \\
\hline C1s & 61.9 & 71.7 & 76.8 & 74.7 \\
\hline O1s & 38.1 & 26.1 & 13.6 & 20.3 \\
\hline N1s & - & 2.2 & 9.6 & 5.1 \\
\hline
\end{tabular}

For all the cases examined, being the three samples of PLLA treated with 100, 200, and 300 pulses, positions of the peaks numbered $\mathrm{C} 1-\mathrm{C} 9, \mathrm{~N} 1-\mathrm{N} 3$ and O1-O5 were the same, and their respective FWHM were very similar. However, depending on the number of pulses used, significant changes in the atomic percentage of carbon and oxygen were observed, as well as changes in the percentage content of nitrogen incorporated (Table 2). In the original non-modified polymer, the atomic percentage of oxygen and carbon was 38.1 and 61.9 at.\%, respectively. As far as the modified PLLA is concerned, with the increase in the number of pulses used, the atomic content of carbon increased comparing to untreated PLLA and was 71.7 at. $\%$ for 100 pulses, 76.8 at. $\%$ for 200 pulses and slightly decreased to 74.7 at. $\%$ for 300 pulses. On the other hand, the content of oxygen decreased after EUV and plasma treatment, comparing to untreated PLLA. For the samples modified with 100 and 200 pulses, the oxygen content lowered to 26.1 and 13.6 at.\%, respectively, and then increased to 20.3 at. $\%$ for the sample modified with 300 pulses. The content of nitrogen incorporated was 2.2 at.\% for the sample modified with 100 pulses, 9.6 at.\% for the one modified with 200 pulses, and 5.1 at.\% for the sample modified with 300 pulses. It is because when $\mathrm{N}_{2}$-plasma and EUV treatment method is used, the ablation process takes place, chemical change on the PLLA surface occurs, and nitrogen atoms are incorporated. As the number of pulses increases (up to 200), the process of incorporation of nitrogen atoms dominates over the ablation process, which leads to the increased content of nitrogen. However, for 300 pulses, the ablation process starts to dominate and results in a decrease in the content of nitrogen.
Summarizing, the $\mathrm{N}_{2}$-plasma and EUV treatment resulted in the change of the morphology of the PLLA surfaces and a radical decomposition of its chemical structure. Changes of both morphology and chemical structure significantly affect the behavior of cells on the polymer surface.

\subsection{Cell culture}

Human dermal fibroblasts (NHDF-Ad) were used for examination of the behavior of cells cultured on pristine and modified with EUV and $\mathrm{N}_{2}$ plasma irradiation PLLA surfaces. The investigations have been performed using fluorescent microscopy after live/dead staining. Figure 5 presents images of adhered cells after $24 \mathrm{~h}$ from seeding on the control sample surface, pristine PLLA, and PLLA modified with 100, 200, and 300 pulses, respectively. No dead cells (no red spots) were observed on any PLLA sample surfaces. It is therefore assumed the cells were comfortable on the surfaces of the samples examined and showed high viability. Independently from the cells' viability observed, the morphology of fibroblasts attached to PLLA surfaces was much more varied compared to the morphology of fibroblasts from the control sample. Control cultures of NHDF-Ad cells were well spread and had elongated spindlelike shape. On the other hand, there were few cells on the surface of non-modified PLLA, and their morphology was rather round, and only single cells were of elongated shape. The number of cells attached to the surface of the PLLA sample modified with 100 pulses was only a little bit higher comparing to untreated PLLA, however the majority of them were elongated in shape. The highest number of cells evenly distributed on the whole foil surface was observed on the PLLA modified with 200 and 300 pulses. The morphology of those cells was also diversified. Many of the cells were of a round shape, as well as elongated shape. Also, some cells observed were closer one to another, whereas the other ones were proliferating. The number of adhered cells on control and PLLA surfaces were given in Table 3.

At the subsequent stage of this biological part of the research, the MTT assay was also performed to examine if polymer surfaces modified with EUV and

Table 3. Number of adhered human dermal fibroblasts after $24 \mathrm{~h}$ from seeding on control sample, untreated PLLA and PLLA modified with 100, 200 and 300 pulses.

\begin{tabular}{|c|c|c|c|c|c|}
\hline Sample & Control & PLLA untreated & PLLA-100 & PLLA-200 & PLLA-300 \\
\hline Number of cells adhered & $162 \pm 12$ & $45 \pm 6$ & $58 \pm 2$ & $76 \pm 9$ & $100 \pm 19$ \\
\hline
\end{tabular}



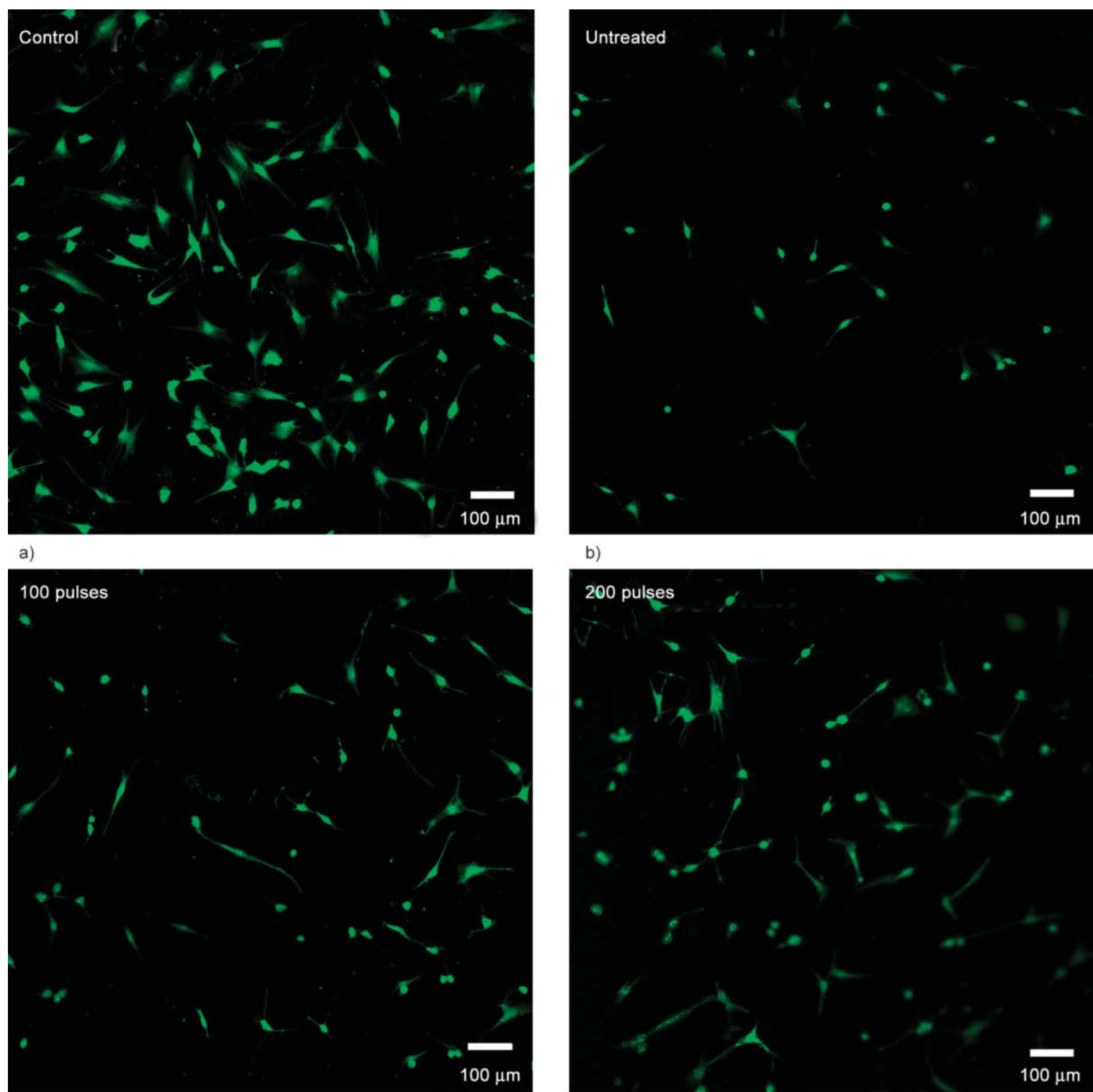

c)

d)

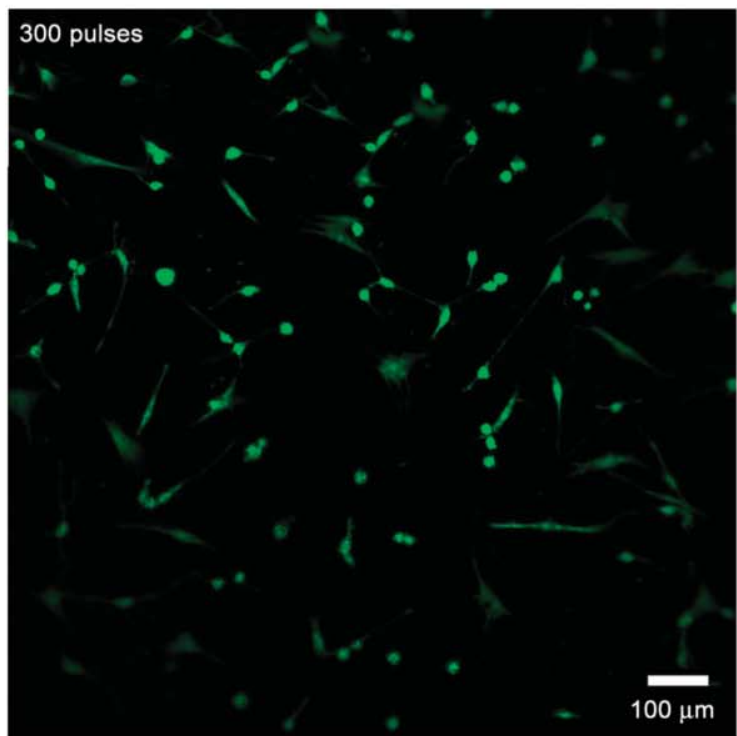

e)

Figure 5. Images of adhered human dermal fibroblasts after $24 \mathrm{~h}$ from seeding on control sample (a), untreated PLLA (b) and PLLA modified with 100, 200 and 300 pulses (d-e). 
photoionizing plasma irradiation had not become cytotoxic to fibroblasts. According to ISO 10993-5 standard, cell viability exceeding $70 \%$ in MTT assay procedure is considered as non-cytotoxicity. For the examined non-modified polymer sample and the ones modified with 100, 200, and 300 pulses the average cell viability examined through MTT assay was $89,92,91$ and $84 \%$, respectively (Figure 6). Therefore, this confirmed that pristine PLLA, as well as PLLA modified with EUV radiation and photoionizing plasma, were not cytotoxic materials, i.e. they do not give cytotoxic effect to fibroblast cells. The increase in the number of cells adhered to the samples modified with 200 and 300 pulses can relate to the fact that these samples had a specific regular pattern, and their roughness was higher comparing to pristine PLLA. Regular pattern and higher roughness may make the surface much more attractive for fibroblasts being very sensitive to surface topography [56] than flat surfaces such as pristine PLLA or even PLLA modified with 100 pulses. As it is known, the surface texture is of important interest in cell adhesion. It has been shown, too, that cells adhere depending on the surface roughness and the rougher surface, the better cell adhesion [41, 56-58]. Moreover, the samples had the highest content of incorporated nitrogen on their surface, and, as it is believed, cell adhesion is improved specifically due to $\mathrm{C}-\mathrm{N}$ and $\mathrm{N}-\mathrm{H}$ bonds that can promote the protein adsorption on the surface [59]. The rounded shape of the cells dominating the pristine PLLA surface and their presence on the modified PLLA surfaces can be perceived as fibroblasts' natural behavior on the first day of incubation. Similar morphology of fibroblastic cells

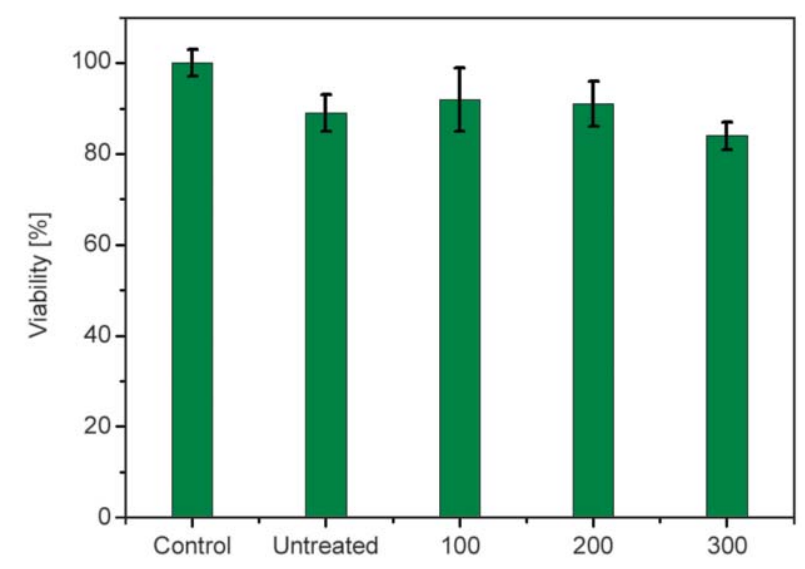

Figure 6. Human dermal fibroblasts viability on control sample, untreated PLLA and PLLA modified with 100,200 and 300 pulses. seeded on PLLA surfaces at the same time interval was also observed by other authors $[60,61]$.

\section{Conclusions}

In this paper, the influence of photoionizing plasma and EUV treatment on physico-chemical properties and cytocompatibility of PLLA surfaces was examined. It was found that the morphology of the PLLA surfaces significantly changed due to the modifications. The micro-pattern appeared on the surfaces, and the average surface roughness increased comparing to the unmodified PLLA. The interaction of $\mathrm{N}_{2}$-plasma and EUV irradiation on the PLLA surfaces also induced dramatic chemical changes in the near-surface layer of PLLA. The decrease of the oxygen content and increase of the carbon content was observed as well as the incorporation of nitrogen atoms and the appearance of the new chemical groups. Cytocompatibility tests clearly show that modifications that led to the incorporation of nitrogen-containing functional groups into the PLLA surface as well as to changes in surface's geometry play an important role in cell adhesion. The increase in the number of adhered NHDF-Ad cells was observed as well as the positive effect on their distribution and viability. However, further detailed research is required in terms of multiple-day cell culture tests.

\section{Acknowledgements}

This work was supported by the National Science Centre, Poland, grant agreement no. UMO-2016/23/B/ST7/00949, partially by the National Science Centre, Poland, grant agreement no. 2019/03/X/ST5/01643, partially by the European Union's Horizon 2020 Programme (LASERLAB-EUROPE) grant agreement no. 654148 and partially by the National Centre for Research and Development under contract no. DOB-1-3/1/PS/2014.

\section{References}

[1] Zhang H., Mittal G.: Biodegradable protein-based films from plant resources: A review. Environmental Progress and Sustainable Energy, 29, 203-220 (2010).

https://doi.org/10.1002/ep.10463

[2] Tawakkal I. S. M. A., Cran M. J., Miltz J., Bigger S. W.: A review of poly(lactic acid)-based materials for antimicrobial packaging. Journal of Food Science, 79, 1477-1490 (2014). https://doi.org/10.1111/1750-3841.12534

[3] Mihindukulasuriya S. D. F., Lim L-T.: Nanotechnology development in food packaging: A review. Trends in Food Science and Technology, 40, 149-167 (2014). https://doi.org/10.1016/j.tifs.2014.09.009 
[4] Rom M., Fabia J., Grübel K., Sarna E., Graczyk T., Janicki J.: Study of the biodegradability of polylactide fibers in wastewater treatment processes. Polimery, 62, 834-840 (2017).

https://doi.org/10.14314/polimery.2017.834

[5] Seyednejad H., Ghassemi A. H., van Nostrum C. F., Vermonden T., Hennink W. E.: Functional aliphatic polyester for biomedical and pharmaceutical applications. Journal of Controlled Release, 152, 168-176 (2011). https://doi.org/10.1016/j.jconrel.2010.12.016

[6] Leja K., Lewandowicz G.: Polymer biodegradation and biodegradable polymers - A review. Polish Journal of Environmental Studies, 19, 255-266 (2010).

[7] Guo B., Ma P. X.: Synthetic biodegradable functional polymers for tissue engineering: A brief review. Science China Chemistry, 57, 490-500 (2014). https://doi.org/10.1007/s11426-014-5086-y

[8] Narayanan G., Vernekar V. N., Kuyinu E. L., Laurencin C. T.: Poly(lactic acid)-based biomaterials for orthopaedic regenerative engineering. Advanced Drug Delivery Reviews, 107, 247-276 (2016).

https://doi.org/10.1016/j.addr.2016.04.015

[9] Lasprilla A. J. R., Martinez G. A. R., Lunelli B. H., Jardini A. L., Filho R. M.: Poly-lactic acid synthesis for application in biomedical devices - A review. Biotechnology Advances, 30, 321-328 (2012).

https://doi.org/10.1016/j.biotechadv.2011.06.019

[10] Li S.: Bioresorbable hydrogels prepared through stereocomplexation between poly(L-lactide) and poly(Dlactide) blocks attached to poly(ethylene glycol). Macromolecular Bioscience, 3, 657-661 (2003).

https://doi.org/10.1002/mabi.200350032

[11] Gong Y., Zhu Y., Liu Y., Ma Z., Gao C., Shen J.: Layerby-layer assembly of chondroitin sulfate and collagen on aminolyzed poly(L-lactic acid) porous scaffolds to enhance their chondrogenesis. Acta Biomaterialia, 3, 677-685 (2007).

https://doi.org/10.1016/j.actbio.2007.04.007

[12] Bergsma J. E., de Bruijn W. C., Rozema F. R., Bos R. R. M., Boering G.: Late degradation tissue response to poly(L-lactide) bone plates and screws. Biomaterials, 16, 25-31 (1995).

https://doi.org/10.1016/0142-9612(95)91092-D

[13] Chen Q., Cao L., Wang J., Jiang L., Zhao H., Yishake M., Ma Y., Zhou H., Lin H., Dong J., Fan Z.: Bioinspired modification of poly(L-lactic acid)/nano-sized $\beta$-tricalcium phosphate composites with gelatin/hydroxyapatite coating for enhanced osteointegration and osteogenesis. Journal of Biomedical Nanotechnology, 14, 884-899 (2018). https://doi.org/10.1166/jbn.2018.2576

[14] Carmagnola I., Chiono V., Abrigo M., Ranzato E., Martinotti S., Ciardelli G.: Tailored functionalization of poly(L-lactic acid) substrates at the nanoscale to enhance cell response. Journal of Biomaterials Science, Polymer Edition, 30, 526-546 (2019). https://doi.org/10.1080/09205063.2019.1580954
[15] Qiao T., Song P., Guo H., Song X., Zhang B., Chen X.: Reinforced electrospun PLLA fiber membrane via chemical crosslinking. European Polymer Journal, 74, 101-108 (2016). https://doi.org/10.1016/j.eurpolymj.2015.11.012

[16] Bastekova K., Guselnikova O., Postnikov P., Elashnikov R., Kunes M., Kolska Z., Švorčik V., Lyutakov O.: Spatially selective modification of PLLA surface: From hydrophobic to hydrophilic or to repellent. Applied Surface Science, 397, 226-234 (2017). https://doi.org/10.1016/j.apsusc.2016.11.062

[17] Szustakiewicz K., Stępak B., Antończak A. J., Maj M., Gazińska M., Kryszak B., Pigłowski J.: Femtosecond laser-induced modification of PLLA/hydroxyapatite composite. Polymer Degradation and Stability, 149, 152-161 (2018). https://doi.org/10.1016/j.polymdegradstab.2018.01.015

[18] Slepička P., Michaljaničová I., Sajdl P., Fitl P., Švorčik V.: Surface ablation of PLLA induced by $\mathrm{KrF}$ excimer laser. Applied Surface Science, 283, 438-444 (2013). https://doi.org/10.1016/j.apsusc.2013.06.127

[19] Slepička P., Slepičková Kasálková N., Pinkner A., Sajdl P., Kolská Z., Švorčík V.: Plasma induced cytocompatibility of stabilized poly-L-lactic acid doped with graphene nanoplatelets. Reactive and Functional Polymers, 131, 266-275 (2018).

https://doi.org/10.1016/j.reactfunctpolym.2018.08.006

[20] Slepička P., Slepičková Kasálková N., Stránská E., Bačáková L., Švorčík V.: Surface characterization of plasma treated polymers for applications as biocompatible carriers. Express Polymer Letters, 7, 535-545 (2013).

https://doi.org/10.3144/expresspolymlett.2013.50

[21] Xia Y., Boey F., Venkatraman S. S.: Surface modification of poly(L-lactic acid) with biomolecules to promote endothelialization. Biointerphases, 5, 32-40 (2010). https://doi.org/10.1116/1.3467508

[22] Nofar M., Sacligil D., Carreau P. J., Kamal M. R., Heuzey M-C.: Poly(lactic acid) blends: Processing, properties and applications. International Journal of Biological Macromolecules, 125, 307-360 (2019). https://doi.org/10.1016/j.ijbiomac.2018.12.002

[23] Zille A., Oliveira F. R., Souto A. P.: Plasma treatment in textile industry. Plasma Processes and Polymers, 12, 98-131 (2015). https://doi.org/10.1002/ppap.201400052

[24] Jaganjac M., Vesel A., Milkovic L., Recek N., Kolar M., Zarkovic N., Latiff A., Kleinschek K. S., Mozetic M.: Oxygen-rich coating promotes binding of proteins and endothelialization of polyethylene terephthalate polymers. Journal of Biomedical Material Research A, 102, 2305-2314 (2014).

https://doi.org/10.1002/jbm.a.34911

[25] Recek N., Jaganjac M., Kolar M., Milkovic L., Mozetič M., Stana-Kleinschek K., Vesel A.: Protein adsorption on various plasma-treated polyethylene terephthalate substrates. Molecules, 18, 12441-12463 (2013). https://doi.org/10.3390/molecules 181012441 
[26] Vallon S., Drévillon B., Poncin-Epaillard F.: In situ spectroellipsometry study of the crosslinking of polypropylene by an argon plasma. Applied Surface Science, 108, 177-185 (1997).

https://doi.org/10.1016/S0169-4332(96)00574-0

[27] Poncin-Epaillard F., Vallon S., Drévillon B.: Illustration of surface crosslinking of different polymers treated in argon plasma. Macromolecular Chemistry and Physics, 198, 2439-2456 (1997).

https://doi.org/10.1002/macp.1997.021980807

[28] Khorasani M. T., Mirzadeh H., Irani S.: Plasma surface modification of poly(L-lactic acid) and poly (lactic-coglycolic acid) films for improvement of nerve cells adhesion. Radiation Physics and Chemistry, 77, 280-287 (2008).

https://doi.org/10.1016/j.radphyschem.2007.05.013

[29] Wan Y., Yang J., Yang J. L., Bei J. Z., Wang S. G.: Cell adhesion on gaseous plasma modified poly-(L-lactide) surface under shear stress field. Biomaterials, 24, $3757-$ 3764 (2003).

https://doi.org/10.1016/S0142-9612(03)00251-5

[30] Khorasani M. T., Mirzadeh H., Irani S.: Comparison of fibroblast and nerve cells response on plasma treated poly(L-lactide) surface. Journal of Applied Polymer Science, 112, 2429-3435 (2009).

https://doi.org/10.1002/app.29813

[31] Nakagawa M., Teroaka F., Fujimoto S., Hamada Y., Kibayashi K., Takahashi J.: Improvement of cell adhesion on poly(L-lactide) by atmospheric plasma treatment. Journal of Biomedical Materials Research A, 77, 112-118 (2006).

https://doi.org/10.1002/jbm.a.30521

[32] Teraoka F., Nakagawa M., Hara M.: Surface modification of poly(L-lactide) by atmospheric pressure plasma treatment and cell response response. Dental Materials Journal, 25, 560-565 (2006).

https://doi.org/10.4012/dmj.25.560

[33] Jiao Y., Xu J., Zhou C.: Effect of ammonia plasma treatment on the properties and cytocompatibility of a poly (L-lactic acid) film surface. Journal of Biomaterials Science, 23, 763-777 (2012).

https://doi.org/10.1163/092050611X560690

[34] Gugala Z., Gogolewski S.: Attachment, growth, and activity of rat osteoblasts on polylactide membranes treated with various low-temperature radiofrequency plasmas. Journal of Biomedical Materials Research A, 76, 288-299 (2006).

https://doi.org/10.1002/jbm.a.30462

[35] Bartnik A., Wachulak P., Fiedorowicz H., Jarocki R., Kostecki J., Szczurek M.: Luminescence of $\mathrm{He}$ and $\mathrm{Ne}$ gases induced by EUV pulses from a laser plasma source. Radiation Physics and Chemistry, 93, 9-14 (2013). https://doi.org/10.1016/j.radphyschem.2013.02.039

[36] Ogura K., Yamada H., Sato Y., Okamoto Y.: Excitation temperature in high-power nitrogen microwave-induced plasma at atmospheric pressure. Applied Spectroscopy, 51, 1496-1499 (1997).

https://oi.org/10.1366/0003702971938984
[37] Bartnik A., Wachulak P., Fok T., Węgrzyński Ł., Fiedorowicz H., Pisarczyk T., Chodukowski T., Kalinowska Z., Dudzak R., Dostal J., Krokusky E., Skala J., Ullschmied J., Hrebicek J., Medrik T.: Photoionized plasmas induced in neon with extreme ultraviolet and soft X-ray pulses produced using low and high energy laser systems. Physics of Plasmas, 22, 043302/1043302/9 (2015).

https://doi.org/10.1063/1.4919024

[38] Bartnik A., Skrzeczanowski W., Czwartos J., Kostecki J., Fiedorowicz H., Wachulak P., Fok T.: Low temperature plasmas induced in $\mathrm{SF}_{6}$ by extreme ultraviolet (EUV) pulses. Physics of Plasmas, 25, 063508/1063508/8 (2018).

https://doi.org/10.1063/1.5030965

[39] Murthy N. S., Prabhu R. D., Martin J. J., Zhou L., Headrick R. L.: Self-assembled and etched cones on laser ablated polymer surfaces. Journal of Applied Physics, 100, 023538/1-023538/12 (2006).

https://doi.org/10.1063/1.2212267

[40] Bartnik A., Lisowski W., Sobczak J., Wachulak P., Budner B., Korczyc B., Fiedorowicz H.: Simultaneous treatment of polymer surface by EUV radiation and ionized nitrogen. Applied Physics A, 109, 39-43 (2012). https://doi.org/10.1007/s00339-012-7243-5

[41] Ul Ahad I., Butruk B., Ayele M., Budner B., Bartnik A., Fiedorowicz H., Ciach T., Brabazon D.: Extreme ultraviolet (EUV) surface modification of polytetrafluoroethylene (PTFE) for control of biocompatibility. $\mathrm{Nu}$ clear Instruments and Methods in Physics Research B, 364, 98-107 (2015). https://doi.org/10.1016/j.nimb.2015.08.093

[42] Bartnik A., Fiedorowicz H., Jarocki R., Kostecki J., Szczurek M., Wachulak P. W.: Laser-plasma EUV source dedicated for surface processing of polymers. Nuclear Instruments and Methods in Physics Research A: Acceleartors, Spectrometers, Detectors and Associated Equipment, 647, 125-131 (2011). https://doi.org/10.1016/j.nima.2011.05.033

[43] Arenholz E., Heitz J., Wagner M., Bäuerle D., Hibs H., Hagemeyer A.: Laser-induced surface modification and structure formation of polymers. Applied Surface Science, 69, 16-19 (1993).

https://doi.org/10.1016/0169-4332(93)90475-Q

[44] Bäuerle D. W.: Laser processing and chemistry. Springer, Berlin (1996).

[45] Arenholz E., Wagner M., Heitz J., Bäuerle D.: Structure formation in UV-laser-ablated polyimide foils. Applied Physics A, 55, 119-120 (1992). https://doi.org/10.1007/BF00324612

[46] Reisnger B., Fahrner M., Frischauf I., Yakunin S., Svorcik V., Fiedorowicz H., Bartnik A., Romanin C., Heitz J.: EUV micropatterning for biocompatibility control of PET. Applied Physics A, 100, 511-516 (2010). https://doi.org/10.1007/s00339-010-5845-3 
[47] Bartnik A., Fiedorowicz H., Jarocki R., Kostecki J., Szczurek M., Chernyayeva O., Sobczak J. W.: EUV-induced physico-chemical changes in near-surface layers of polymers. Journal of Electron Spectroscopy and Related Phenomena, 184, 270-275 (2011).

https://doi.org/10.1016/j.elspec.2010.12.030

[48] Bartnik A., Fiedorowicz H., Jarocki R., Kostecki J., Szczurek M., Biliński A., Chernyayeva O., Sobczak J. W.: Physical and chemical modifications of PET surface using a laser-plasma EUV source. Applied Physics A, 99, 831-836 (2010). https://doi.org/10.1007/s00339-010-5596-1

[49] Bartnik A., Fiedorowicz H., Burdyńska S., Jarocki R., Kostecki J., Szczurek M.: Combined effect of EUV irradiation and acetone treatment on PET surface. Applied Physics A, 103, 173-178 (2011). https://doi.org/10.1007/s00339-010-5982-8

[50] Jacobs T., Morent R., De Geyter N., Dubruel P., Leys C.: Plasma surface modification of biomedical polymers: Influence on cell-material interaction interaction. Plasma Chemistry and Plasma Processing, 32, 1039-1073 (2012).

https://doi.org/10.1007/s11090-012-9394-8

[51] Novis Y., Pireaux J. J., Berzini A., Petit E., Caudano R., Lutgen P., Feyder G., Lazare S.: Structural origin of surface morphological modifications developed on poly (ethylene terephthalate) by excimer laser photoablation. Journal of Applied Physics, 63, 365-370 (1988). https://doi.org/10.1063/1.341436

[52] Briggs D.: Surface analysis of polymers by XPS and static SIMS. Cambridge University Press, Cambridge (1998).

[53] Rytlewski P., Mróz W., Żenkiewicz M., Czwartos J., Budner B.: Laser induced surface modification of polylactide. Journal of Materials Processing and Technology, 212, 1700-1704 (2012).

https://doi.org/10.1016/j.jmatprotec.2012.03.019

[54] Khan M. K., Luo J., Wang Z., Khan R., Chen X., Wan Y.: Alginate dialdehyde meets nylon membrane: A versatile platform for facile and green fabrication of membrane adsorbers. Journal of Materials Chemistry B, 6, 1640-1649 (2018).

https://doi.org/10.1039/c7tb02966g
[55] Pels J. R., Kapteijn F., Moulijn J. A., Zhu Q., Thomas K. M.: Evolution of nitrogen functionalities in carbonaceous materials during pyrolysis. Carbon, 33, 16411653 (1995). https://doi.org/10.1016/0008-6223(95)00154-6

[56] Berry C. C., Campbell G., Spadiccino A., Robertson M., Curtis A. S. G.: The influence of microscale topography on fibroblast attachment and motility. Biomaterials, 25, 5781-5788 (2004). https://doi.org/10.1016/j.biomaterials.2004.01.029

[57] Eisenbarth E., Meyle J., Nachtigall W., Breme J.: Influence of the surface structure of titanium materials on the adhesion of fibroblasts. Biomaterials, 17, 1399-1403 (1996). https://doi.org/10.1016/0142-9612(96)87281-4

[58] Lotfi M., Nejib M., Naceur M.: Cell adhesion to biomaterials: Concept of biocompatibility. in 'Advances in Biomaterials Science and Biomedical Applications' (ed.: Pignatello R.) IntechOpen, London, 207-240 (2013). https://doi.org/10.5772/53542

[59] Yokota T., Terai T., Kobayashi T., Meguro T., Iwaki M.: Cell adhesion to nitrogen-doped DLCs fabricated by plasma-based ion implantation and deposition method using toluene gas. Surface and Coatings Technology, 201, 8048-8051 (2007).

https://doi.org/10.1016/j.surfcoat.2006.03.051

[60] Yamaguchi M., Shinbo T., Kanamori T., Wang P-C., Niwa M., Kawakami H., Nagaoka S., Hirakawa K., Kamiya M.: Surface modification of poly(L-lactic acid) affects initial cell attachment, cell morphology, and cell growth. Journal of Artificial Organs, 7, 187-193 (2004). https://doi.org/10.1007/s10047-004-0267-7

[61] Jacobs T., Declercq H., De Geyter N., Cornelissen R., Dubruel P., Leys C., Beaurain A., Payen E., Morent R.: Plasma surface modification of polylactic acid to promote interaction with fibroblasts. Journal of Materials Science: Materials in Medicine, 24, 469-478 (2013). https://doi.org/10.1007/s10856-012-4807-z 